\title{
PENGEMBANGAN PIRAMIDA PASCAL DALAM PENYELESIAN PERSOALAN MATEMATIKA PEMANGKATAN SUKU TIGA
}

\section{THE DEVELOPMENT OF PASCAL PYRAMIDS IN THE COMPLETION OF MATHEMATIC TRINOMIAL}

\section{DEDY YUSUF ADITYA}

Program Studi Informatika, Universitas Indraprasta PGRI

\author{
TB. Simatupang, JI. Nangka Raya No.58 C, RT.5/RW.5, Tj. Bar., Kec. Jagakarsa, \\ Kota Jakarta Selatan, Daerah Khusus Ibukota Jakarta 12530 \\ Ponsel : 083898230036 \\ Surel: yusufadit42@yahoo.co.id
}

\begin{abstract}
Abstrak
Tujuan dari penulisan artikel ini adalah untuk menyelesaikan persoalan yang sering dialami oleh siswa Sekolah Menengah Pertama dan sedrajat atau siswa Sekolah Menengah Atas dan sedrajat dalam menyelesaikan persoalan matematika yang berkaitan dengan pemangkatan suku dua dan juga suku tiga. Disamping itu juga artikel ini juga bertujuan untuk mempermudah siswa dalam mengerjakan soal dengan tingkat kesulitan yang tinggi yang berkaitan dengan pemangkatan suku dua dan juga suku tiga. Membrikan pemahaman kepada siswa tentang konsep segitiga pascal dan juga piramida pascal serta cara menyusun rumus untuk pemangkatan suku dua dan juga suku tiga. Metode penelitian yang digunakan dalam artikel ini adalah metode pengembangan atau $R$ \& $D$ dan juga studi pustaka. Hasil penelitian adalah 1) ekspansi dari segitiga pascal untuk menyusun bilangan binomial $(a+b)^{\mathrm{n}}$. 2) ekspansi dari piramida pascal untuk menyusun bilangan binomial $(\mathrm{a}+\mathrm{b}+\mathrm{c})^{\mathrm{n}}$.
\end{abstract}

Kata Kunci : segitiga pasca, pyramidal pascal, suku tiga

\begin{abstract}
The purpose of writing this article is to solve problems that are often experienced by students of junior Hight School and is equivalent and High senior School students and is equivalent in solving mathematical problems related to the appointment of second and third terms. Besides that, this article also aims to make it easier for students to work on problems with a high level of difficulty related to the appointment of terms two and three. Give students an understanding of the concept of the pascal triangle and also the pascal pyramid and how to develop formulas for the appointment of terms two and three terms. The research method used in this article is the method of development or R\&D and also library research. The results of the study are 1) the expansion of the pascal triangle to construct binomial numbers ( $a+$ $b)^{n}$. 2) expansion of the pascal pyramid to arrange binomial numbers $(a+b+c)^{n}$.
\end{abstract}

Keywords: post triangle, pyramidal pascal, trinomial 


\section{PENDAHULUAN}

Matematika adalah disiplin ilmu yang berdiri sendiri dalam mempelajari hal yang kesemuanya berkaitan dengan penalaran. Matematika merupakan salah satu pengetahuan tertua dan dianggap sebagai induk atau alat dan bahasa dasar banyak ilmu. Matematika terbentuk dari penelitian bilangan dan ruang yang merupakan suatu disiplin ilmu yang berdiri sendiri dan tidak merupakan cabang dari ilmu pengetahuan alam. Matematika dipelajari siswa mulai dari sekolah dasar sampai perguruan tinggi. Matematika memiliki banyak sekali cabang ilmu seperti aritmatika, geometri, aljabar, trigonometri, statistic dan juga kalkukulus. Yang umum dipelajari di sekolah adalah cabang ilmu aljabar.

Pemangkatan suku dia dipelajari pada jenjang sekolah menengah pertama (SMP) dan juga sekolah menengah kedua. Namun kenyataanya siswa sulit untuk mempelajari pemangkatan suku dua. Siswa sekolah menengah atas juga mempelajari pemangkatan suku dua dan juga pemangkatan suku tiga, namun pada kenyataanya siswa menyelesaikan pemangkatan suku dua dan suku tiga dengan metode perkalian berulang. Memang metode ini adalah metode umum yang digunakan siswa untuk menyelesaikan soal pemangkatan suku dua dan pemangkatan suku tiga, namun hal ini efektif ababila pangkat bilangan binomialnya masih dalam kategori kecil. Metode itu akan sulit diterapkan dan membutuhkan waktu yang lama apabila pangkat binomialnya besa, butuh waktu yang sangat lama untuk menye;lesaikan satu soal saja.

Segitiga pascal, merupakan suatu pola bilangan yang sangat unik. Sebab, semua bilangan pembentukannya akan membentuk segitiga dengan pola - pola penjumlahan tersendiri. Kegunaan dari segitiga pascal adalah untuk memudahkan penyelesaian persoalan matematika yang berkaitan dengan pemangkatan suku dua dengan pangkatnya merupakan bilangan bulat yang $\geq 0$, dimana koofisien awal dari kedua variabel adalah sama (syahdiyah, 2013 : 579).

Sebagai contoh, misalkan yang digunakan adalah variabel $a$ dan $b$, dengan $x$ merupakan koefisien awal dari kedua variabel $a$ dan $b$, serta $n$ sebagai bilangan bulat yang $\geq 0$ merupakan pangkat atau eksponen dari variabel $a$ dan $b$, kemudian 
bentuk pemangkatan suku dua

saat ini dilandasi karena tersebut dikalikan dengan sebuah perkembangan matematika pada konstanta (c), maka dapat dibuat sebuah persamaan sebagai berikut:

$$
\begin{aligned}
c(x a+x b)^{n} & =c[(x a+x b) \\
& \times(x a+x b) \times \ldots . . \\
& \times(x a+x b)]
\end{aligned}
$$

Selain itu, ada pula kegunaan lain dari segitiga pascal adalah untuk menyatakan kebenaran dari setiap bilangan riel $(R)$, dimana setiap bilangan yang bernilai riel akan memiliki lebih dari satu bilangan pembentuk segitiga pascal, dengan jumlah keseluruhan suku pada baris tertentu dan jumlah keseluruhan suku pada semua baris, untuk setiap segitiga pascal yang di hasilkan akan sama dengan bilangan yang bernilai riel tersebut. Hal ini disebabkan karena setiap bilangan pangkat $(n)$ yang diambil merupakan sembarang bilangan bulat yang tidak bernilai negatif, atau : $0 \leq n \leq \infty$.

\section{KAJIAN TEORITIK}

Matematika adalah ilmu
universal yang mendasari dari
perkembangan teknologi modern saat
ini, memiliki peran yang penting dalam
berbagai disiplin serta untuk
memajukan daya pikir manusia.
Perkembangan pesat pada bidang
teknologi informasi serta komunikasi


abad ke-10 dengan ulasan tahapan ini segitiga pascal masih dalam Chandas Shastra, sebuah buku dapat digunakan yaitu dengan India purba dalam prosodi bahasa Sanskrit yang ditulis oleh Pingala antara abad ke-5-ke-2 SM. Karya Pingala pula hanya muncul tentang pecahan, yang diulas oleh Halayudha, sekitar 975, menggunakan segi tiga itu untuk menjelaskan rujukan kabur pada Meru-prastaara, "Tangga Gunung Meru". la juga disedari bahawa pepenjuru pada jumlah segi tiga itu wujud pada nombor Fibonacci. ahli matematik India Bhattotpala (kk. 1068) kemudian memberikan barisan 0-16 pada segi tiga tersebut. (Adi, 2011).

Dalam pembelajaran Matematika, kemampuan uintuk menjabarkan dan membuat generalisasi sangat penting bagi guru dalam membantu siswa mengembangkan kemampuan berpikir matematis. Penerapan segitiga pascal untuk menentukan ekspansi $(a+b)^{n}$ sudah dipelajari sejak sekolah menengah. Yang menjadi pertanyaan apakah siswa mampu menerapkannya dalam menyelesaikan pesoalan pemangkatan suku dua dengan segitiga pascal?. Hal yang lebih penting lagi bagaimana siswa mneyelesaikan $(a+b+c)^{n}$. Dalam 
sampai dengan tingkat ke 7 .

Namun sebenarnya segitiga pascal sampai tingkat yang tak terhiingga.

Kegunaan dari segitiga pascal adalah untuk menentukan koefisien-koefisien binomial untuk menyatakan bentuk aljabar dengan suku dua atau dua peubah. Berikut gambar dan penjelasanya:

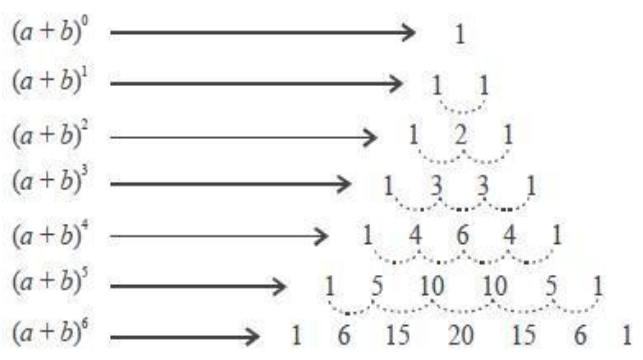

Gambar 2. Segitiga Pascal dan Fungsi Koefisiennya

Berikut penjelasan penyusunan (ekspansi) pemangkatan suku dua dari gambar segitiga pascal di atas :

1) $(a+b)^{0}=1$

2) $(a+b)^{1}=1 a^{1} b^{0}+1 a^{0} b^{1}$

3) $(a+b)^{2}=1 a^{2} b^{0}+2 a^{1} b^{1}+$ $1 a^{0} b^{2}$

4) $(a+b)^{3}=1 a^{3} b^{0}+3 a^{2} b^{1}+$ $3 a^{1} b^{2}+1 a^{0} b^{3}$

5) $(a+b)^{4}=1 a^{4} b^{0}+4 a^{3} b^{1}+$ $6 a^{2} b^{2}+4 a^{1} b^{3}+1 a^{0} b^{4}$

6) $(a+b)^{5}=1 a^{5} b^{0}+5 a^{4} b^{1}+$ $10 a^{3} b^{2}+10 a^{2} b^{3}+5 a^{1} b^{4}+$ $1 a^{0} b^{5}$
7) $(a+b)^{6}=1 a^{6} b^{0}+6 a^{5} b^{1}+$ $15 a^{4} b^{2}+20 a^{3} b^{3}+15 a^{2} b^{4}+$ $6 a^{1} b^{5}+1 a^{0} b^{6}$

8) Dan seterusnya Melihat pola yang terbentuk dari koefisien pangkatdua peubah dan pangkat dari masing-masing peubah dapat dilihat bahwa :

1) Nilai a dari depan ke belakang, mulai pangkat tertinggi terus kebelakang dikurang 1 sampai dengan pangkat nol.

2) Nilai b dari depan ke belakang mulai pangkat nol terus kebelakang bertambah 1 sampai dengan pangkat tertinggi.

Sehingga secara umum bentuk $(a+b)^{n}$ dapat dinyatakan dalam rumus $\quad(a+b)^{n}=\sum_{k=0}^{n} a^{n-k} b^{k}$ dikombinasikan dengankoefisien dari segitiga pascal.

Sebagai contoh : tentukan hasil dari $\quad(4 x+2 y)^{3} \quad$ dengan menggunakan koefisien segitiga pascal maka p[enyelesaian dari soal di atas adalah :

$$
\begin{gathered}
(4 x+2 y)^{3}=1(4 x)^{3}+3(4 x)^{2}(2 y) \\
+3(4 x)(2 y)^{2} \\
+1(2 y)^{3} \\
(4 x+2 y)^{3}=64 x^{3}+96 x^{2} y+48 x y^{2} \\
+8 y^{3}
\end{gathered}
$$

Untuk menjawab persoalan pemangkatan suku tiga dalam 
matematika seperti $(a+b+c)^{n}$ pertanyaan ini bisa dijawab dengan cara klasik yaitu cara perkalian berulang, namun membutuhkan waktu yang lama apalagi jika pangkatnya tinggi. Dengan mengembangkan segitiga pascal yang dapat digunakan dalam menjawab pemangkatan suku dua, maka diusunlah piramida pascal sebagai gabungan dari tiga buah segitiga pascal yang disusun menjadi sebuah limas segitiga (Piramida) sebagai penyusun koefisien-koefisien pemangkatan tiga suku.

Sebagai contoh untuk $n=$ $0,1,2,3$ dan 4 berturut-turut diperoleh :

$$
\begin{aligned}
(a+b+c)^{0}=1 & \\
(a+b+c)^{1}= & a+b+c \\
(a+b+c)^{2}= & (a+b+c)(a+b+c) \\
& =a^{2}+2 a b+b^{2} \\
& +2 a c+2 b c+c^{2} \\
(a+b+c)^{3} & \\
& =(a+b+c)(a+b \\
& +c)(a+b+c) \\
& =a^{3}+3 a^{2} b+3 a^{2} c \\
& +3 a b^{2}+6 a b c \\
& +3 a c^{2}+b^{3}+3 b^{2} c \\
& +3 b c^{2}+c^{3}
\end{aligned}
$$

$$
\begin{aligned}
(a+b+c)^{3} & \\
& =(a+b+c)(a+b \\
& +c)(a+b+c) \\
& =a^{3}+3 a^{2} b+3 a^{2} c \\
& +3 a b^{2}+6 a b c \\
& +3 a c^{2}+b^{3}+3 b^{2} c \\
& +3 b c^{2}+c^{3} \\
(a+b+c)^{4} & \\
& =(a+b+c)(a \\
& +b+c)(a+b \\
& +c)(a+b+c) \\
& =a^{4}+4 a^{3} b \\
& +4 a^{3} c+6 a^{2} b^{2} \\
& +12 a^{2} b c+6 a^{2} c^{2} \\
& +4 a b^{3}+12 a b^{2} c \\
& +12 a b c^{2}+4 a c^{3} \\
& +b^{4}+4 b^{3} c \\
& +6 b^{2} c^{2}+4 b c^{3} \\
& +c^{4}
\end{aligned}
$$

Dari contoh ekspansi di atas, terlihat bahwa banyak suku dari ekspansi $(a+b+c)^{n}$ dengan $n$ mulai dari $0,1,2,3$ dan 4 secara berturut-turut adalah 1, 3, 6 , 10, daqn $15, \ldots$ bilanganbilangan tersebut merupakanbarisan bilangan segitiga. Pola bilangan segitiga adalah pola bilangan yang terbentuk dari suatu pola bilangan-bilangan yang membentuk segitiga. Rumus pola 
bilangan segitiga yaitu $\mathrm{U}_{\mathrm{n}}=$ $\frac{1}{2} n(n+1)$.

Perhatikan

gambar

piramida pascal berikut yang terbentuk dari tiga buah segitiga pascal yang disusun menjadi bangun ruang tiga dimensi menjadi limas segitiga (Piramida) dengan bilangan pascal.

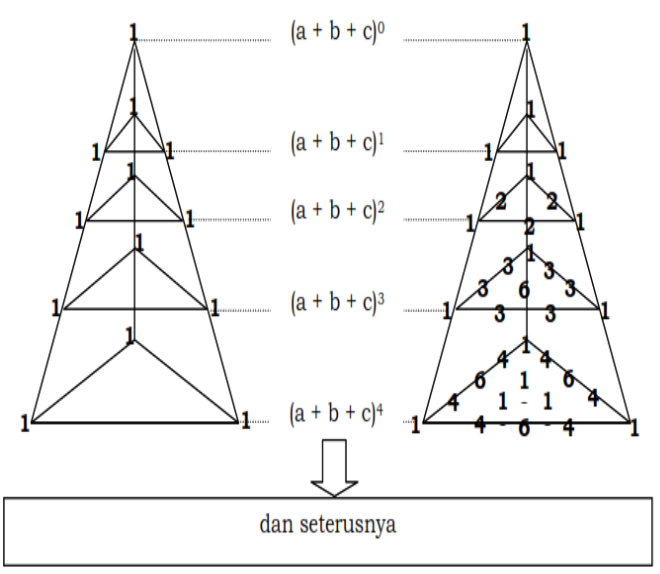

Gambar 3. Penyusunan

Koefisien Piramida Pascal

Jika kita kupas gambar piramida di atas dalam gambar dua dimensi maka gambar piramida pascal akan terbentuk sebagai berikut :

1) Untuk $(a+b+c)^{0}$ mempunyai koefisien tunggal yaitu 1 , seperti yang ada pada puncak gambar piramida pascal

2) Untuk $(a+b+c)^{1}$ gambar yang terbentuk adalah :

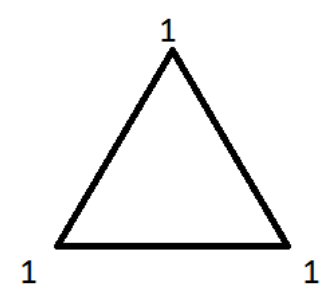

Gambar 4. Irisan Piramida Pascal Tingkat 2

Artinya $\quad(a+b+c)^{1}=1 a+$ $1 b+1 c$

3) Untuk $(a+b+c)^{2}$ gambar yang terbentuk adalah :

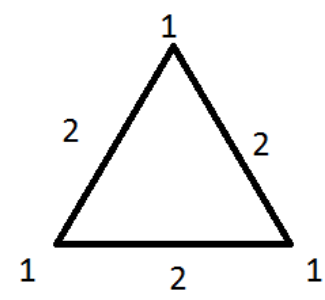

Gambar 5. Irisan Piramida Pascal Tingkat 3 Gambar ini diperoleh dari

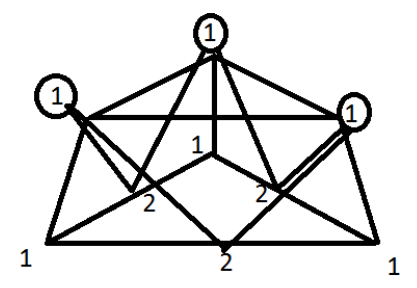

Gambar 6. Irisan Piramida

Pascal Tingkat 2 dan 3

Artinya $\quad(a+b+c)^{2}=1 a^{2}+$ $2 a b+1 b^{2}+2 a c+1 c^{2}+2 b c$

4) Untuk $(a+b+c)^{3}$ gambar yang terbentuk adalah : 


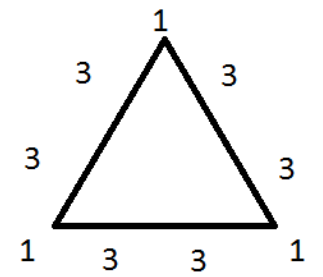

Gambar 7. Irisan Piramida Pascal Tingkat 4

Namun pada pembahasan di atas banyaknya suku yang terbentuk pada piramida pascal tingkat ke 4 dari atas adalah 10. Sedangkan koefisien yang terbentuk di atas adalah 9. Maka ada satu koefisien yang harusnya berada di tengah yaitu adalah koefisien 6 .

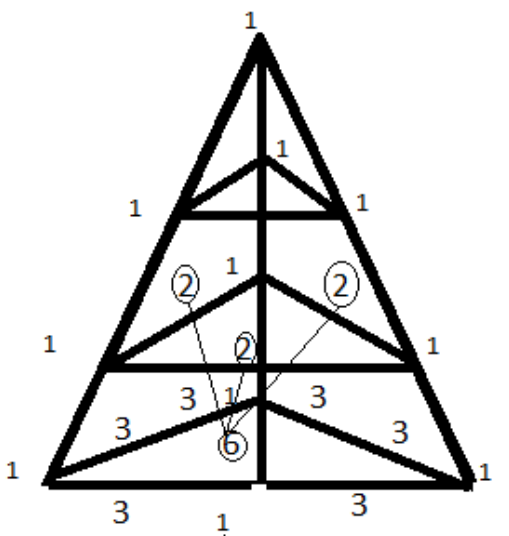

Gambar 8. Piramida Pascal dalam penyusunan Koefisien

Koefisien pada piramida pascal yang terbentuk adalah 1,3,3,1,3,3,6,1,3,3, koefisien 6 terbentuk dari penjumlahan koefisien $2+2+2$ pada piramida tingkat 3 dari atas sehingga berjumlah 6 .

Bagaimana menempatkan variable beserta pangkatnya pada $(a+b+c)^{3}$ perhatikan gambar berikut :

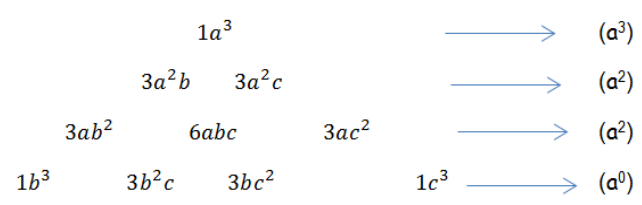

Gambar 9. Penyususnan

Koefisien dan variable pada

paramida pascal tingkat 4

Pola yang terbentuk pada variable a dimulai dari baris pertama $a^{n}$ baris ke dua adalah $a^{n-1}$, baris ke tiga adalah $a^{n-2}$ sampai terakhir adalah $a^{n-n}$.

Pola yang terbentuk pada variable $b$

$$
\begin{aligned}
& b^{\mathrm{o}} \\
& b^{1} b^{0} \\
& b^{2} b^{1} b^{0} \\
& b^{3} \quad b^{2} \quad b^{1} \quad b^{0}
\end{aligned}
$$

Gambar 10. Penyususnan variable (b) pada paramida pascal tingkat 4

Pola yang terbentuk untuk variable c adalah: 


$$
\begin{aligned}
& c^{\mathrm{O}} \\
& c^{0} \quad c^{1} \\
& c^{0} \quad c^{1} c^{2} \\
& c^{0} \quad c^{1} \quad c^{2} \quad c^{3}
\end{aligned}
$$

Gambar 11. Penyususnan variable (c) pada paramida pascal tingkat 4

Artinya $\quad(a+b+c)^{3}=1 a^{3}+$ $3 a^{2} b+3 a b^{2}+6 a b c+1 b^{3}+$ $3 b^{2} c+3 b c^{2}+1 c^{3}+3 a^{2} c+$ $3 a c^{2}$

5) Untuk $(a+b+c)^{4}$ gambar yang terbentuk adalah :

Pada tingkat 4 dari atas, kita telah menemukan pola penyusunya. Pada segitigas pascal untuk pangkat 4 koefisienya adalah 1,4,6,4,1 segingga jika dalam piramida pascal polanya akan menjadi:

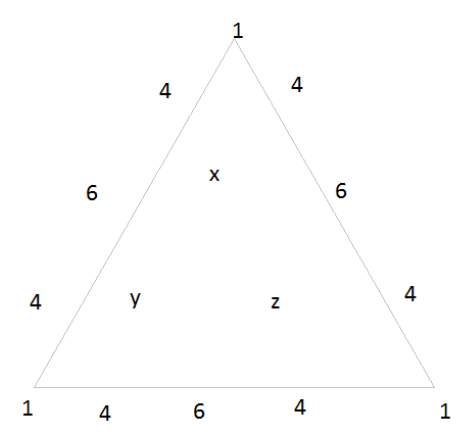

Gambar 12. Irisan Piramida Pascal tingkat 5

Ada tiga koefisien yang akan di cari yaitu $x, y$ dan $z$.
Bilangan penyusun untuk menentukan nilai $\mathrm{x}, \mathrm{y}$ dan $\mathrm{z}$ diperoleh dari koefisien dari tingkat 4 , seperti berikut :

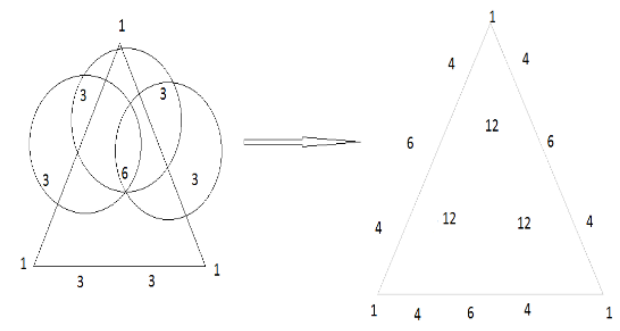

Gambar 13. Penyusun koefisien Piramida Pascal tingkat 5

$X$ merupakan penjumlahan dari 3 buah bilangan yaitu $3+6+3=12$

$Y$ merupakan penjumlahan dari 3 buah bilangan yaitu $3+3+6=12$

Z merupakan penjumlahan dari 3 buah bilangan yaitu $6+$ $3+3=12$

Sehingga dalam menyusun $(a+b+c)^{4}$ adalah 144612 641212414641

Menyusun koefisien beserta variabelnya sebagai berikut :

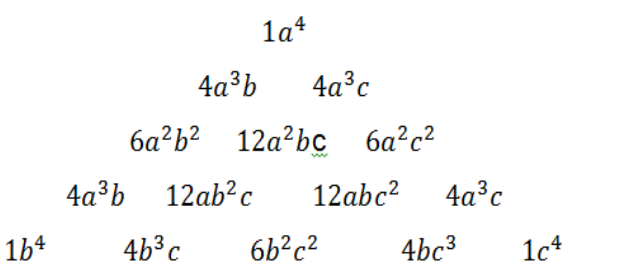

Gambar 12. Penyusunan koefisien dan Variabel 
Piramida Pascal tingkat 5

Sehingga $(a+b+c)^{4}=1 a^{4}+$ $4 a^{3} b+4 a^{3} c+6 a^{2} b^{2}+$

$12 a^{2} b c+6 a^{2} c^{2}+4 a^{3} b+$

$12 a b^{2} c+12 a b c^{2}+4 a^{3} c+$ $1 b^{4}+4 b^{3} c+6 b^{2} c^{2}+4 b c^{3}+$ $1 c^{4}$

Secara umum dalam

menentukan $(a+b+c)^{n}$

dapat dirumuskan dengan

$\sum_{r=0}^{n}\left(\begin{array}{l}n \\ r\end{array}\right) a^{n-r} \sum_{j=0}^{r}\left(\begin{array}{l}r \\ j\end{array}\right) b^{r-j} c^{j}$

\section{SIMPULAN}

Berdasarkan Hasil Pembahasan yang telah dipaparkan di atas dapat ditarik beberapa simpulan diantaranya

1. Segitiga pascal dapat digunakan untuk menyelesaikan persoalan matematika $(a+b)^{n}$. dengan rumus $(a+b)^{n}=\sum_{k=0}^{n} a^{n-k} b^{k}$.

2. Segitiga pascal dapat dikembangkan menjadi piramida pascal untuk menyelesaikan persoalan matematika $(a+b+$ $c)^{n}$ dapat dirumuskan dengan $(a+b+c)^{n}=$ $\sum_{r=0}^{n}\left(\begin{array}{l}n \\ r\end{array}\right) a^{n-r} \sum_{j=0}^{r}\left(\begin{array}{l}r \\ j\end{array}\right) b^{r-j} c^{j}$

\section{DAFTAR PUSTAKA}

I Wayan Puja Astawa. "Piramida Pascal : Suatu Pengembangan
Segitiga Pascal" dalam artikel yang tidak dipublikasikan.

Naga, Dali S. Berhitung : Sejarah dan Pengembanganya. Jakarta : Gramedia,1980.

Zumrotus Syadiyah. Pengembangan Segitiga Pascal untuk Memudahkan Penyelesaian Persoalan Matematika yang Berkaitan dengan Pemangkatan Suku Dua. Dalam Jurnal Bimafika. Volume 5. N0 1, 2013. 